\title{
Focal dysplasia of the cerebral cortex in epilepsy
}

\author{
D. C. TAYLOR ${ }^{1}$ AND M. A. FALCONER \\ From the Neurosurgical Unit of Guy's, Maudsley, and King's College Hospitals, London \\ and \\ C. J. BRUTON AND J. A. N. CORSELLIS \\ From the Department of Neuropathology, Runwell Hospital, Wickford, Essex
}

SUMMARY An unusual microscopic abnormality has been identified in the lobectomy specimens removed surgically from the brains of 10 epileptic patients. The abnormality could seldom be identified by palpation or with the naked eye. Histologically, it consisted of congregations of large, bizarre neurones which were littered through all but the first cortical layer. In most, but not in all cases, grotesque cells, probably of glial origin, were also present in the depths of the affected cortex and in the subjacent white matter. This kind of abnormality appears to be a malformation. The picture is reminiscent of tuberous sclerosis but too many distinguishing features, both in the clinical and in the pathological aspects, make this diagnosis untenable. The cases are therefore looked on provisionally (since all but one are still alive) as comprising a distinct form of cortical dysplasia in which localized, exotic populations of nerve cells underlie the electrical and clinical manifestations of certain focal forms of epilepsy.

- During the last 20 years about 300 patients in the Neurosurgical Unit of the Guy's, Maudsley, and King's College Hospitals have had some part of one cerebral hemisphere removed because they were seriously handicapped by intractable epilepsy. The area of brain resected in each patient has depended on the pattern of attacks, on the results of air and

- angiographic studies, and, above all, on the localization of abnormal electrical activity. The standard

- practice has been to remove all or most of one lobe in a single fragment. In most cases this has been the temporal lobe, but frontal and occipital operations have also been carried out. Irrespective of the location, the specimen has nearly always been large - enough to permit the detailed histological study of several convolutions and usually of the full coronal

p extent of the lobe.

Some kind of structural abnormality has been found in about four out of every five of these specimens (Falconer, Serafetinides, and Corsellis, 1964). The findings have ranged from the occasional 'small tumour' or hamartoma (Cavanagh, 1958) to the much commoner sclerosis of the medial tem_ poral areas (Meyer, Falconer, and Beck, 1954).

${ }^{1}$ Present address: Park Hospital for Children, Headington, Oxford.
The purpose of the present paper is to record another kind of structural anomaly that now appears to be distinctive enough to stand on its own.

\section{PATIENTS}

Ten epileptic patients have been studied, eight men and two women. Eight were operated on in the Guy's-Maudsley-King's Neurosurgical Unit by one of the present authors (M.A.F.), one was operated on by Mr. A. Hulme in the Frenchay Hospital, Bristol, and one by Mr. J. Andrew in Oldchurch Hospital, Romford. Six of the patients underwent a temporal lobectomy, three had an anterior frontal ablation, one an occipital lobectomy and one a parietal gyrectomy. (One patient had two operations.)

The age of the patients at the onset of the epilepsy ranged from 2 years to 35 years, and the age at operation from 17 to 46 years. The interval between onset and operation varied from three to 35 years (Table 1).

The specimens, with the exception of the parietal gyrectomy, consisted of the major part of one lobe, as show $\mathrm{n}$ in the diagram for each patient. The specimens were cut into five or six $1.0 \mathrm{~cm}$-thick coronal blocks. Frozen and paraffin embedded sections were 
TABLE

\begin{tabular}{|c|c|c|c|c|c|c|c|}
\hline Case no. & $\begin{array}{l}\text { Family } \\
\text { history } \\
\quad \text { of }\end{array}$ & $\begin{array}{l}\text { Age } \\
a t \\
(y r)\end{array}$ & Clinical summary and fit pattern* & $\begin{array}{l}\text { Pre-op. } \\
\quad I Q\end{array}$ & Skull & Follow-up & Pathology \\
\hline Sex & Epilepsy & First fit & & $\begin{array}{l}(W B I) \\
\text { Verbal }\end{array}$ & $X-r a y$ & Length $(y r)$ & Macroscopic \\
\hline \multirow[t]{2}{*}{ Site of op. } & $\begin{array}{c}\text { Mental } \\
\text { deficiency }\end{array}$ & \multirow[t]{2}{*}{$O p$} & & $\begin{array}{l}\text { Perfor- } \\
\text { mance }\end{array}$ & \multirow[t]{2}{*}{$A E G$} & \multirow[t]{2}{*}{ Result to mid-1970 } & \multirow[t]{2}{*}{ Microscopic } \\
\hline & $\begin{array}{l}\text { Tuberous } \\
\text { sclerosis }\end{array}$ & & & Full scale & & & \\
\hline 1 & \multirow{3}{*}{-} & \multirow{3}{*}{$\frac{7}{26}$} & \multirow{3}{*}{$\begin{array}{l}\text { B. wt. } 5 \mathrm{lb} \text {. Poor scholar. } \\
\text { Employed only in family busi- } \\
\text { ness. Head and eyes to R } \\
\text { followed by G.M. Prolonged } \\
\text { confusional automatisms. } \\
\text { Night attacks }\end{array}$} & \multirow{3}{*}{$\begin{array}{l}\text { V. } 100 \\
\text { P. } 80 \\
\text { F. } 89\end{array}$} & \multirow{2}{*}{$\begin{array}{l}\text { Frontal } \\
\text { hyper- } \\
\text { ostosis }\end{array}$} & 5 & Expanded ill-defined striate areg \\
\hline $\mathbf{F}$ & & & & & & \multirow{2}{*}{$\begin{array}{l}\text { Fit free } 3 \text { yr. Recently } \\
\text { married }\end{array}$} & \multirow{2}{*}{$\begin{array}{l}\text { Striate area: disturbed lamina- } \\
\text { tion. Many abnormal neurons? } \\
\text { and glia }\end{array}$} \\
\hline L. occ. & & & & & Normal & & \\
\hline 2 & + & 2 & \multirow{3}{*}{$\begin{array}{l}\text { Onset ? after fall on head. } \\
\text { Major fits seldom. 'Absences' } \\
\text { and akinetic attacks frequent. } \\
\text { Son epileptic }\end{array}$} & \multirow{3}{*}{$\begin{array}{l}\text { Not tested } \\
\text { but 'a bit } \\
\text { dim' }\end{array}$} & Normal & 3 & \multirow{3}{*}{$\begin{array}{l}\text { F1 and F2: disturbed lamina- } \\
\text { tion. Abnormal neurones }\end{array}$} \\
\hline $\mathbf{F}$ & - & \multirow[t]{2}{*}{37} & & & \multirow{2}{*}{$\begin{array}{l}\text { L. ant. } \\
\text { horn sl. } \\
\text { dilated }\end{array}$} & \multirow[t]{2}{*}{$\begin{array}{l}\text { Fit free since op. Remains } \\
\text { isolated and inadequate }\end{array}$} & \\
\hline L. fr. & - & & & & & & \\
\hline 3 & \multirow{3}{*}{-} & 19 & \multirow{3}{*}{$\begin{array}{l}\text { First fit } 1 \text { yr. after H.I. } \\
\text { Aura in groin. } \\
\text { Destructive automatisms. } \\
\text { Violent }\end{array}$} & \multirow{3}{*}{$\begin{array}{l}\text { V. } 115 \\
\text { P. } 105 \\
\text { F. } 110\end{array}$} & Normal & 3 & \multirow{2}{*}{$\begin{array}{l}\text { Expanded F3 gyrus with ill- } \\
\text { defined corticomedullary } \\
\text { junction }\end{array}$} \\
\hline $\mathbf{M}$ & & \multirow[t]{2}{*}{45} & & & \multirow{2}{*}{$\begin{array}{l}\text { L lat. } \\
\text { vent }>\text { R }\end{array}$} & \multirow{2}{*}{$\begin{array}{l}\text { Fit free } 3 \text { yr. Barbiturate } \\
\text { addict. Contact lost }\end{array}$} & \\
\hline R. fr. & & & & & & & $\begin{array}{l}\text { Excess of large neurones. Mant } \\
\text { abnormal ? glia in deeper } \\
\text { layers }\end{array}$ \\
\hline 4 & + & \multirow[t]{2}{*}{$\begin{array}{c}15 \\
(? 7)\end{array}$} & \multirow{3}{*}{$\begin{array}{l}\text { Normal school. G.Ms from } \\
15 \text { yr. Seizures triggered by } \\
\text { contact on } R \text { face }\end{array}$} & \multirow{3}{*}{$\begin{array}{l}\text { V. } 130 \\
\text { P. } 122 \\
\text { F. } 130\end{array}$} & Normal & 5 & \multirow{3}{*}{$\begin{array}{l}\text { Op. Minute vascular and } \\
\text { neuronal malformation in } \\
\text { parietal area } \\
\text { P.M. Malformed neurones } \\
\text { ? glia adjacent to parietal ses } \\
\text { Gross olivary hypertrophy } \\
\text { many abnormal cells }\end{array}$} \\
\hline $\mathbf{M}$ & - & & & & Normal & Occasional fit for $3 \mathrm{yr}$., then & \\
\hline L. par. & - & 18 & & & & & \\
\hline 5 & + & 13 & First fit one day after H.I. & V. 96 & Normal & $1 \frac{1}{2}$ yr. after 2 nd op. & lst op. (temp. lobe) Normal $\rightarrow$ \\
\hline $\mathbf{M}$ & - & & Occasional minor fit. Fits at & F. 95 & Normal & Fit free. Auras continue. & Normal \\
\hline R. temp. & - & $\begin{array}{l}20 \\
28\end{array}$ & $\begin{array}{l}\text { relief after temporal lobectomy } \\
\text { followed by frontal lobectomy }\end{array}$ & & & At work & 2nd op. (frontal) Normal \\
\hline & & & & & & & $\begin{array}{l}\text { Orbitofront. convexity- } \\
\text { disturbed lamination with } \\
\text { abnormal neurones and glia }\end{array}$ \\
\hline 6 & - & 9 & ? P.M. after ear infection. & V. 111 & Minor & 10 & Poorly defined junction of \\
\hline $\mathbf{M}$ & - & 28 & pre-ictal vasomotor changes. & F. 110 & & Married and emigrated. & and fusiform gyrus \\
\hline R. temp. & - & & & & $\begin{array}{l}R \text { lat. } \\
\text { vent. }\end{array}$ & $1-2$ fits a year & $\begin{array}{l}\text { T2, T3, and fusiform gyrus: } \\
\text { grossly abnormal neurones } \\
\text { and glia }\end{array}$ \\
\hline 7 & - & 31 & Unable to cope with work. & $\begin{array}{l}\text { V. } 93 \\
\text { P. } 98\end{array}$ & post.-op. & 15 & Normal \\
\hline $\mathbf{M}$ & - & 46 & $\begin{array}{l}\text { ritual automatisms and } \\
\text { automatic behaviour }\end{array}$ & F. 94 & on $\mathrm{L}$ side & $\begin{array}{l}\text { Fit free. 1-2 fleeting 'turns' } \\
\text { a year. At work }\end{array}$ & $\begin{array}{l}\text { Collateral sulcus: bizarre } \\
\text { neurones and glia in cortex }\end{array}$ \\
\hline L. temp. & - & & & & normal & & and underlying white matter \\
\hline 8 & - & 14 & Normal child until nocturnal & V. 73 & Minor & 5 & Normal \\
\hline $\mathbf{M}$ & - & 17 & at tacks with aggressive & F. 73 & & Infrequent fits have continued. & $\mathrm{T} 1, \mathrm{~T} 2$, fusiform and para- \\
\hline L. temp. & - & & behaviour & & $\begin{array}{l}\text { sl. anl. } \\
\text { L ant. } \\
\text { horn }\end{array}$ & $\begin{array}{l}\text { Less aggressive. Evidence ot } \\
\text { epileptic focus in opposite } \\
\text { temporal lobe }\end{array}$ & $\begin{array}{l}\text { hippocampal gyrus: disturbec } \\
\text { lamination, abnormal neuron }\end{array}$ \\
\hline
\end{tabular}


TABLE-continued

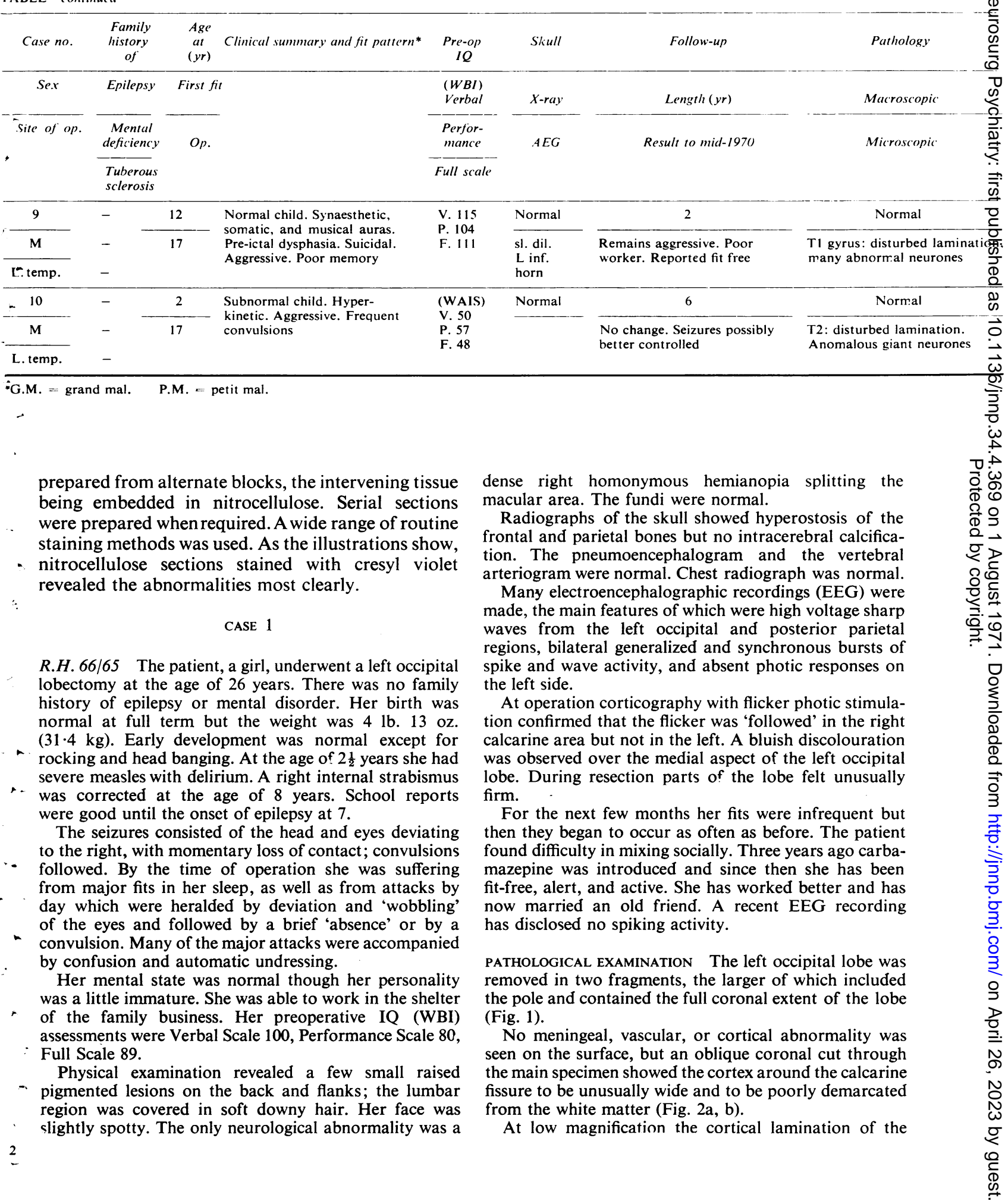




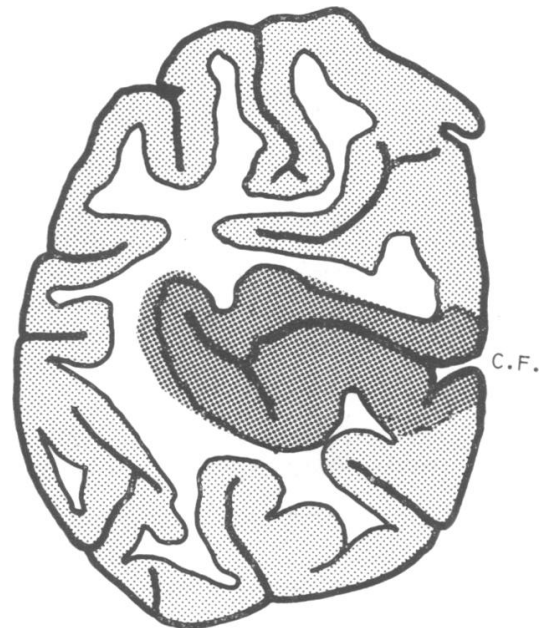

FIG. 1. Case 1. Drawing made from a coronal cut through the resected occipital lobe. The dark shading indicates the abnormal zone around the calcarine fissure (C.F.).

striate area was seen to be totally disrupted by the presence of many abnormally large, rounded, neurones scattered randomly through all but the first layer (Fig. 3a, b). The nuclei and the cytoplasm of these large nerve cells stained unusually intensely with cresyl violet and had an excessively tigroid appearance. The cells were clearly and selectively outlined by their deep impregnation in silver (Gros-Bielschowsky) preparations.

There was a generalized increase of astrocytes in all cortical layers but in the deeper layers grotesquely abnormal cells were present. These were often monstrously large, occasionally with a 'dumb-bell' or a double nucleus, and their cytoplasm had a frosted, glassy look with a smeared outline (Fig. 4a, b). Many of these cells, which recalled those seen in tuberous sclerosis, appeared more like neurones than glia; others resembled glia rather than neurones.

These bizarre cells spread into the white matter deep to the striate cortex where there was some lack of myelin and an excess of properly formed glial cells and fibres. No sub-pial 'wheatsheafing' of glial fibres was demonstrated nor was any calcification found.

A remarkable feature of the specimen was the way in which the anomaly was limited to the striate area. The junction between the normal and abnormal cortex is seen in Fig. 5.

CASE 2

R.H. 165/67 This patient, of German and Polish extraction, was 37 years old when the anterior part of her left frontal lobe was removed. She had four healthy siblings. Her mother had suffered for several years from hypertension and occasional convulsive attacks and a maternal aunt was epileptic.

Nothing is known about the patient's birth or early history. Epileptic attacks started when she was 2 yea $\overline{6}$ old, reputedly after a fall on the head. Convulsions have been rare but brief 'absences' and minor motor or akinet attacks lasting a few seconds occurred regularly everg few days with infrequent fit-free intervals. She becan depressed when her marriage broke down and the question of surgical treatment of her epilepsy was raised by Dr. Ro Fox, the psychiatrist to whom she had been referred. He had found her a little retarded mentally.

Repeated EEG recordings (Dr. June Dickson and Dr. N. de M. Rudolf) revealed continuous 3 to $4 \mathrm{~Hz}$

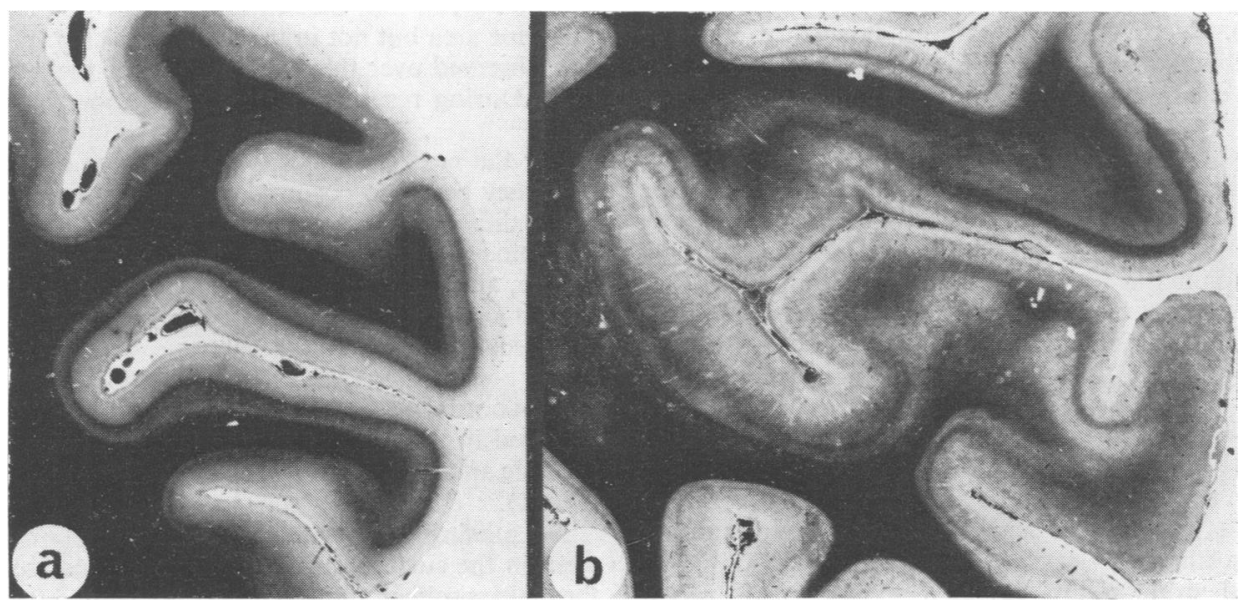

FIG. 2. a. Normal striate area with adjacent cortex and white matter for comparison with: b. the striate area of case 1, showing the considerable widening of the cortical ribbon and the subjacent lack of myelin. Myelin stain, $a$ and $b, \times 3$. 


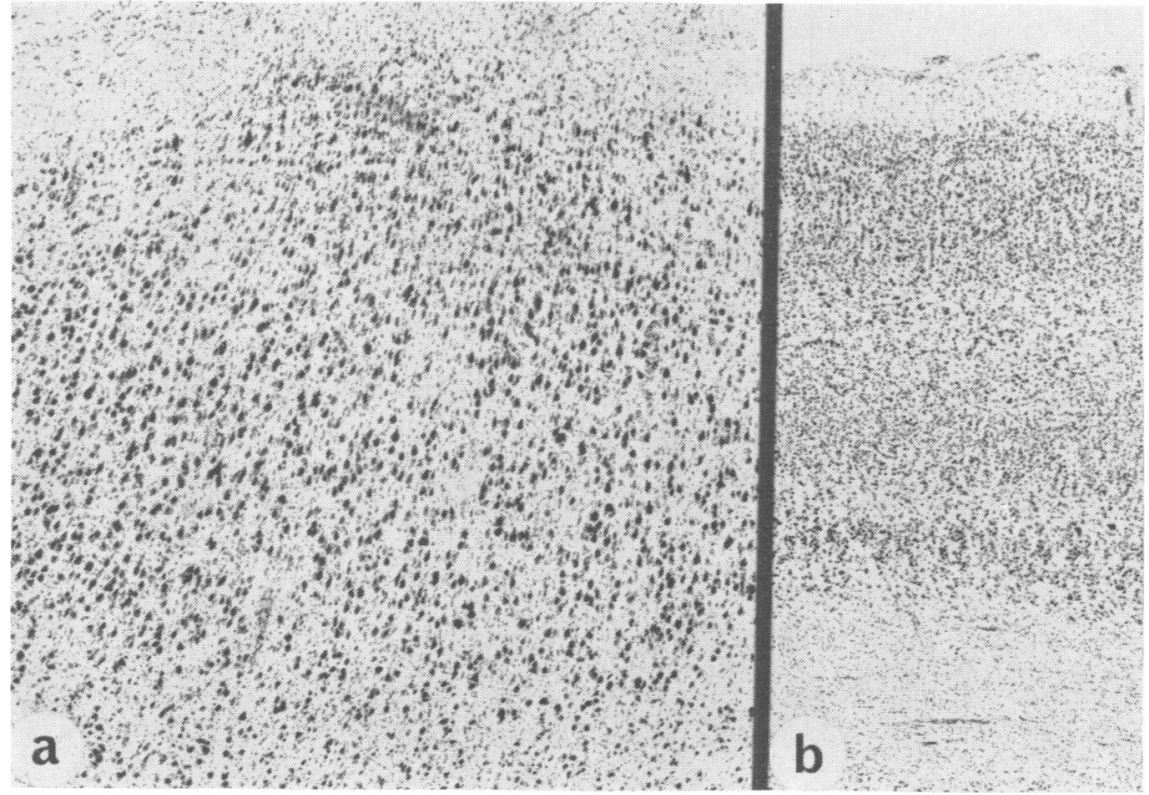

FIG. 3. a. Case 1. Vast population of large anomalous neurones spread through all but the first cortical layer. The cortex is widened and the lamination is lost. b. Normal striate cortex for comparison with, and at the same time magnification as, a. Cresyl violet, $a$ and b, $\times 30$.

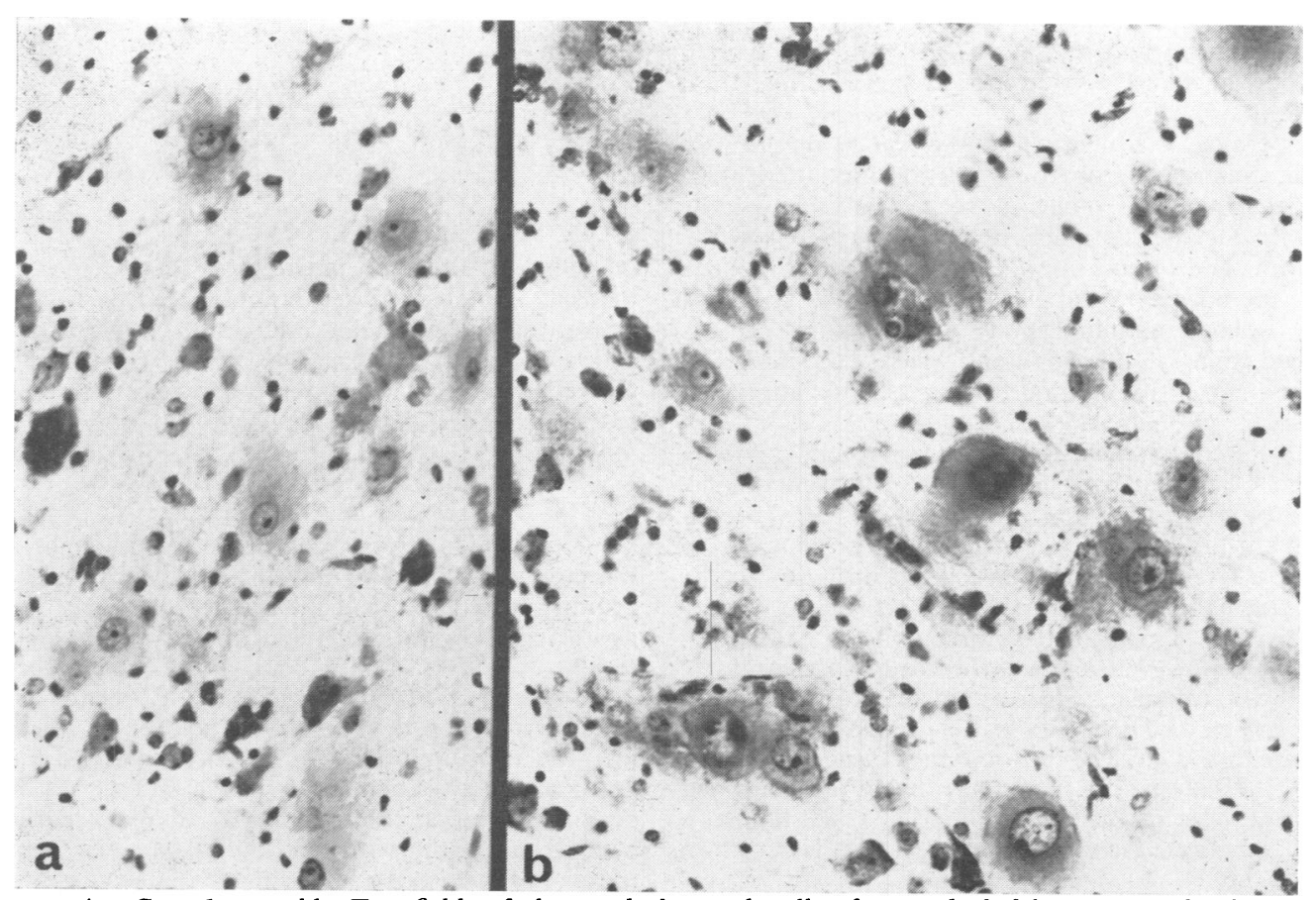

FIG. 4. Case 1. a and b. Two fields of abnormal glia, with cells of more doubtful origin, in the deeper layers of the cortex and the adjacent white matter. Cresyl violet, $a \times 250, b \times 500$. 


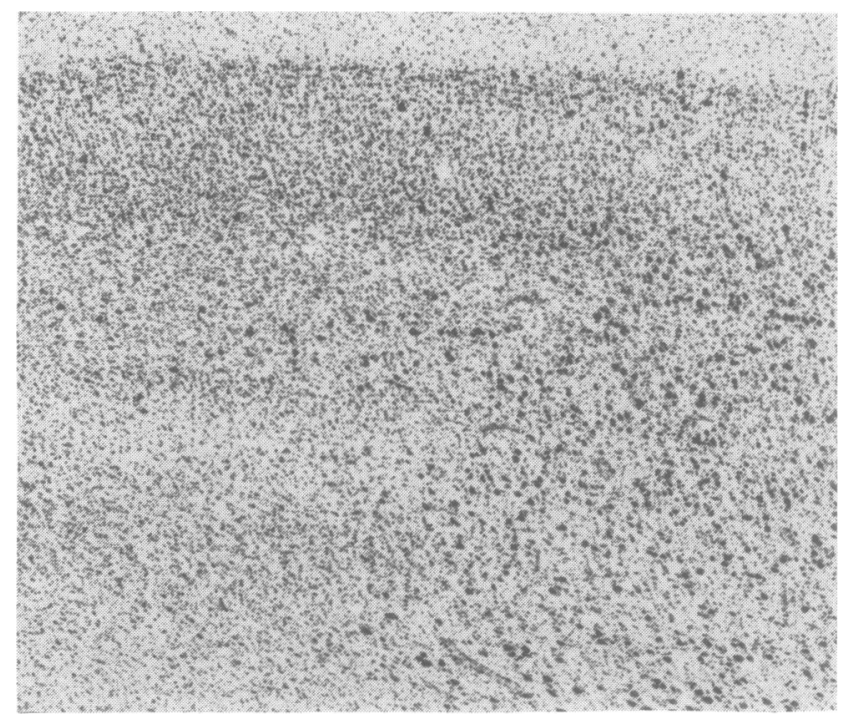

FIG. 5. Case 1. Junction between normal and $\stackrel{\overrightarrow{2}}{\underset{2}{2}}$ abnormal cortex, showing the gradual build up on the right of an alien population of large neurones. Cresyl violet $\times 27$.

slow wave and spike complexes which were maximal $6.0 \mathrm{~cm}$ left of the midline and $6.0 \mathrm{~cm}$ back from the midpoint of the superior orbital margin. A pneumoencephalogram showed the left anterior horn to be minimally dilated. Carotid angiography was normal.

At craniotomy the surface of the brain appeared normal. Electrocorticography picked up spike activity over the superior and middle frontal gyri. The anterolateral part of the left frontal lobe was excised by $\mathrm{Mr}$. J. Andrew.

Postoperative examination of the patient revealed no classical stigmata of tuberous sclerosis, but there were numerous pigmented moles along the hair line of the scalp with facial acne and keratosis follicularis on the upper arms and thighs.

Since the operation three years ago she has remained socially isolated and inadequate. Her young son has developed epilepsy and has recently been taken into care. So far she herself has had no further epileptic attacks.

PATHOLOGICAL EXAMINATION The resected specimen consisted of the anterior part of the left frontal lobe, the line of resection running obliquely down the convexity from a point on its superomedial border $7.0 \mathrm{~cm}$ behind the frontal pole to one $3.0 \mathrm{~cm}$ posterior to the frontal pole on its lateral orbital margin (Fig. 6).

The fixed specimen looked normal to the naked eye. Microscopy, however, showed the cortex in the middle of the three frontal gyri to contain many exceptionally large deeply stained neurones scattered randomly through all but the first layer. The crown of the affected gyrus was spared, the anomalous neurones being concentrated around the base of the sulcus (Fig. 7a). The difference between an affected and an unaffected area is shown in Fig. 7b.

The anomalous neurones were frequently as large as a Betz cell. The nuclear rim often appeared thickened and

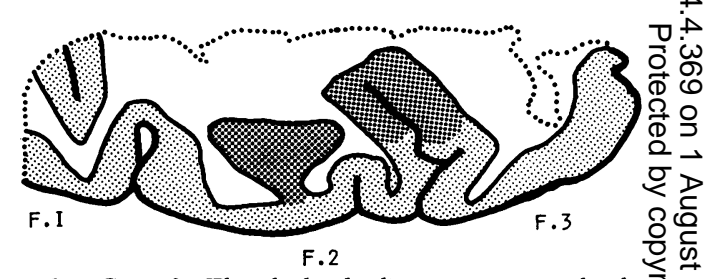

FIG. 6. Case 2. The dark shading represents the lints of the affected cortex in the middle and inferior frontal giv (F2 and F3).

the Nissl substance seemed disorganized (Fig. 8a, b) the cells impregnated deeply and selectively with silvero There were a few small scattered areas of neuronal los@ and astrocytic proliferation, which was particularly marked in the molecular layer. The white matter subjacen? to the affected cortex was poorly myelinated.

\section{CASE 3}

M. 41/57 This man underwent a partial right fronta. lobectomy at the age of 45 years. His father had been aroaggressive alcoholic and his aged mother had died in 2 . psychiatric hospital, but there was no family history of epilepsy.

Nothing is known of the patient's birth or early history; at school he was an average pupil. He injurec his head in a cycle accident when he was 18 years ol\$ and was unconscious for a few minutes. His first fi. occurred a year later and he soon had about five seizure $\overline{\text { Ju }}$ a day. These began with a feeling of pins and needles is the groin and epigastrium; he then became unaware of his surroundings and performed destructive automatisms N His recovery took several hours. Occasional grand maf 


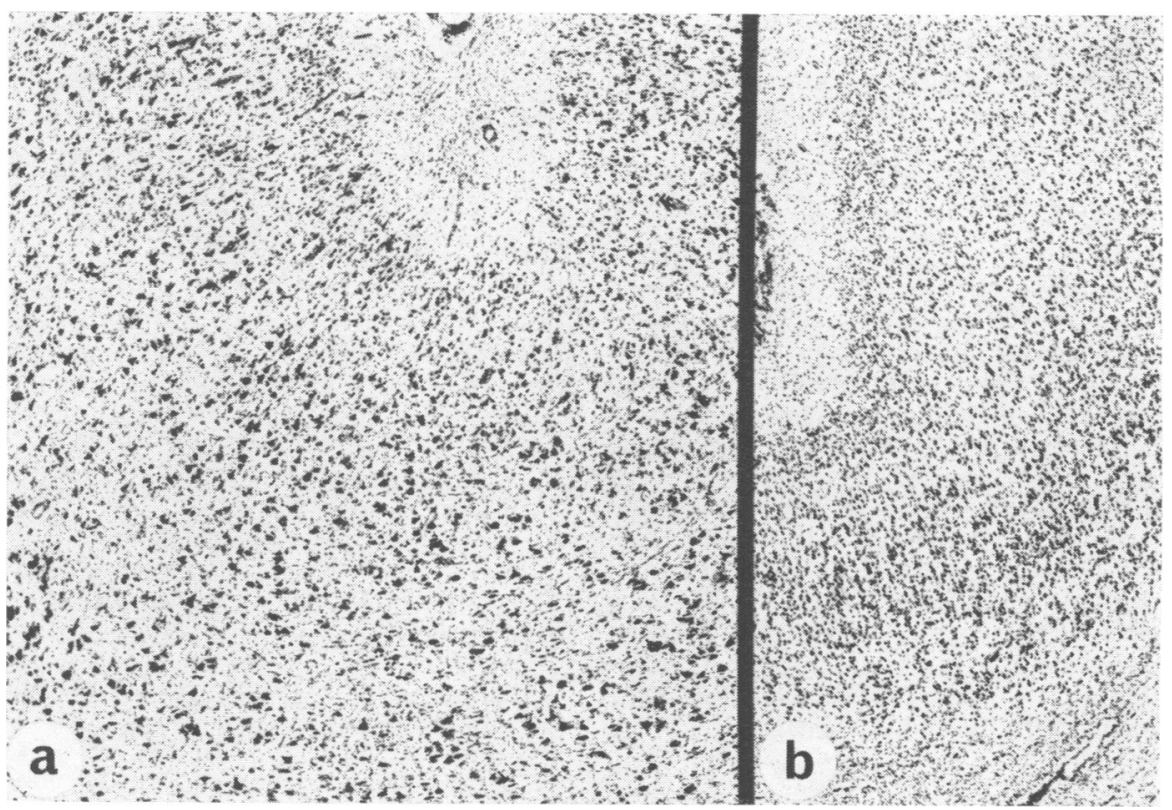

FIG. 7. Case 2. a. Many large exotic neurones in all but the first cortical layer. b. An adjacent unaffected strip of cortex. Cresyl violet, $a$ and $\mathrm{b}, \times 30$.

attacks occurred. The fits continued, with one gap of nine years, until he was admitted for operation.

At this time he was depressed, paranoid, and subject to bouts of uncontrollable rage. His IQ (WBI) assessments were Verbal Scale 115, Performance Scale 105, and Full Scale 110. Physical examination showed a fibroma of the right elbow and a pale naevoid rash on the lower abdomen. There were no neurological abnormalities.

A pneumoencephalogram showed that the left lateral ventricle was slightly larger than the right. A right carotid angiogram was normal. EEG recordings showed spike activity in the right frontal region which was increased by bemegride. Electrocorticography localized the spike focus

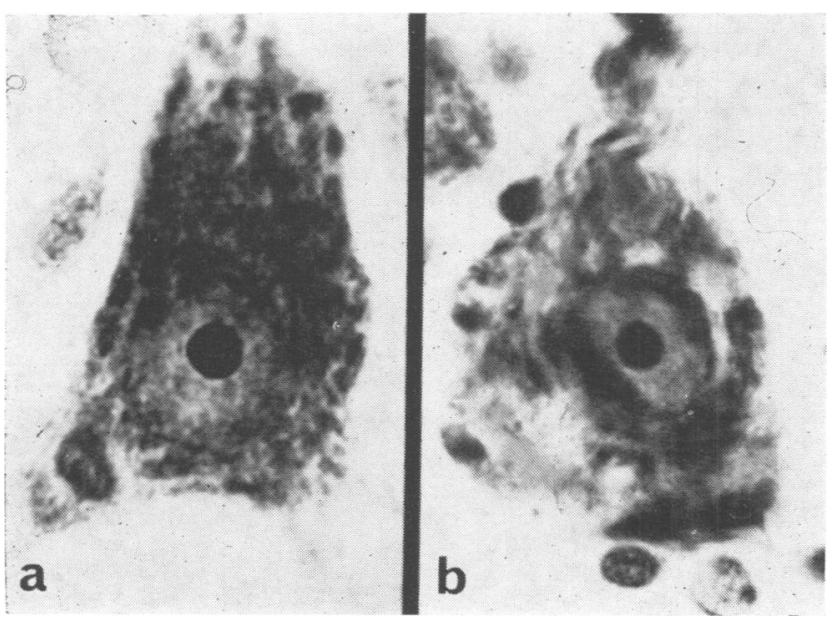

FIG. 8. a. Normal Betz cell for comparison with: b. anomalous 'giant' neurone in cortex of case 2. The Nissl substance has a bizarre, disorganized look; the nuclear rim shows two crescentic thickenings. Cresyl violet, $a$ and $b$, $\times 1,000$. 
to the right frontal pole and at operation the anterior $6.0 \mathrm{~cm}$ of the lobe were resected.

An EEG recording one year after operation showed no spike discharges. He had no fits during the next three years and anticonvulsant drugs were withdrawn. He later became addicted to barbiturates and had to be kept in hospital for a long period. Contact with him has now been lost.

PATHOLOGICAL EXAMination The fixed specimen consisted of the anterior $6.0 \mathrm{~cm}$ of the right frontal lobe, with the adjacent medial and orbital gyri (Fig. 9). On coronal slicing the cortical ribbon of the inferior frontal gyrus was seen to be unusually thick and its junction with the digital white matter was blurred. The affected region measured about $2.5 \mathrm{~cm}$ in diameter.

Microscopy showed many aberrant, large neurones in all but the first cortical layer (Fig. 10a, b, c). These cells were similar to those seen in the previous cases. The subcortical white matter contained many bizarre, often multinucleate, astrocytes with opalescent cytoplasm (Fig. 11). Moderate numbers of such cells were present in the molecular layer of the cortex. The cortex and white matter around this zone appeared normal.
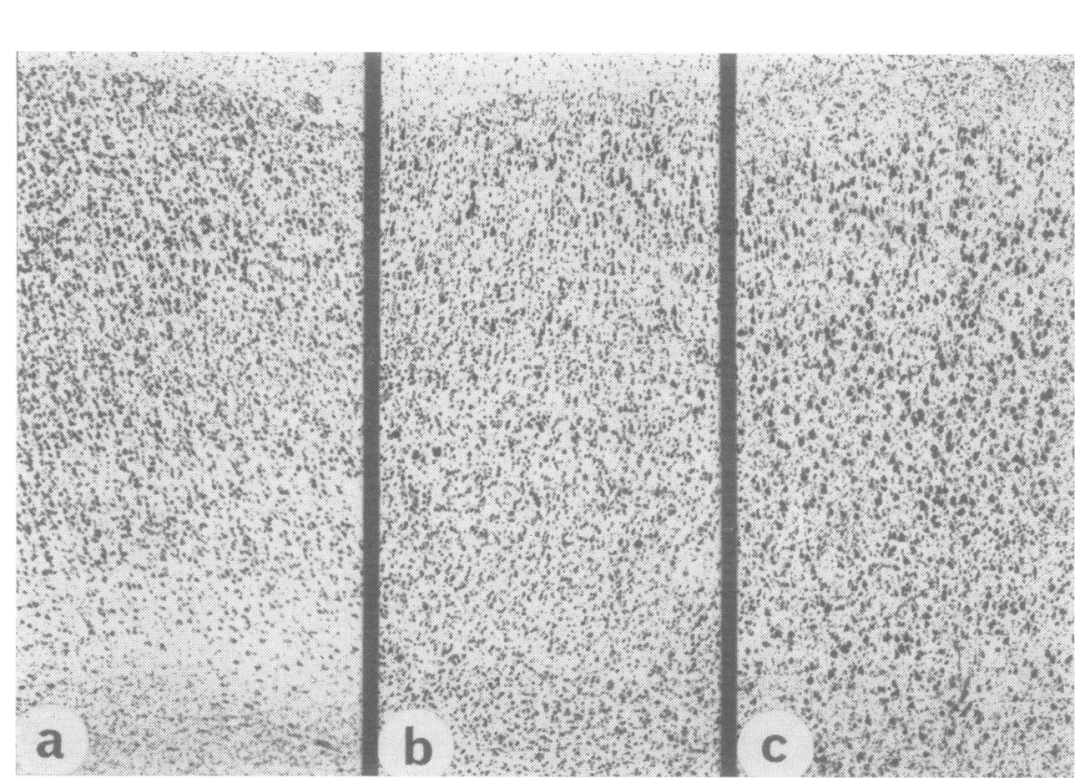

CASE 4

M. 2732 This patient has already been the subject of an extensive psychiatric and EEG study (Goldie and Green, $\vec{\circ}$ 1959). He was 18 years old at the time of operation. His father's sister had died during a bout of convulsions when 3 years old; a maternal cousin was epileptic.

The patient's birth and early development were normal and after grammar school he became a clerk. During

FIG. 9. Case 3. Outline of coronal cut through the frontal resection. The affected area lies in the inferior frontal $\vec{D}$ gyrus (F3) and the white matter deep to this.

FIG. 10. Case 3. Three fields from adjacent areas: a. unaffected cortex, b. large neurones scattered in small numbers at edge of lesion, c. abnormal cortex heavily overpopulated with large neurones. Cresyl violet, $a, b$, and $c, \times 30$.

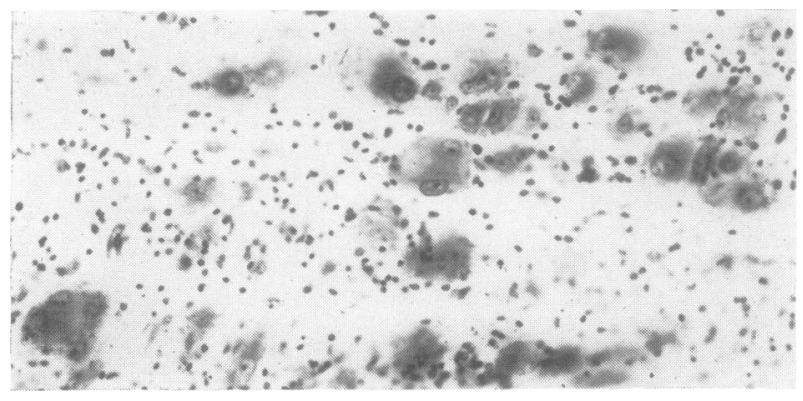

FIG. 11. Case 3. Bizarre cells in the white matter deep to the affected cortex. Cresyl violet $\times 140$. 
mumps, at the age of 7 , he twice fell limply over the breakfast table. Thereafter he complained that once or twice a month he experienced a curious fleeting sensation in his right arm. At the age of 15 he developed nocturnal convulsions, and subsequently he found that a chance contact on the right side of his face could trigger off a throbbing sensation in the face and the right arm which might lead to a fit in which the whole body would stiffen. After a forced expiratory groan the right arm would rise while the head and eyes would rotate to the left. In rare attacks without an aura he would fall. He was aware of events during the seizures but was unable to speak. Since there were refractory periods of one to two hours after attacks, he sometimes provoked them for convenience; otherwise they occurred spontaneously three or four times a day and were uncontrolled by drugs.

His mental state was normal; his IQ assessments before operation (WBI) were Verbal Scale 130, Performance Scale 122, Full Scale 130. No physical abnormality was found. Radiography of the skull and pneumoencephalograms were normal. EEG recordings showed an active spike focus over the left parasagittal area. When a seizure was provoked it was accompanied by a burst of moderate voltage 16 to $20 \mathrm{~Hz}$ activity over the left central area.

At craniotomy the fronto-parietal region was exposed and appeared normal. Electrocorticography implicated an area adjacent to the superior border of the left parietal lobe immediately behind the post-central gyrus. A block of tissue $2 \times 3 \mathrm{~cm}$ was removed, embedded in which a small arteriovenous malformation $0.4 \mathrm{~cm}$ $1.5 \mathrm{~cm}$ was found. The diagnosis was confirmed histologically (Dr. S. Strich).

For the next year the patient led a more active life; during this time he had three self-induced fits. An EEG a year after operation showed only occasional spikes in the left central region. An attempt to induce a seizure by rubbing the left side of his face failed on this occasion. Three years later he married and ceased self-stimulation at the request of his wife. Spontaneous attacks, however, gradually became more frequent and returned to several a day. Further surgery was being considered when five years after operation he went into status epilepticus at another hospital and died 11 days later, after a period of hypotension with suspected cardiac arrest. At postmortem examination (Dr. D. H. Johnson) death was attributed to bronchopneumonia.

MACROSCOPY OF BRAIN The fixed brain weighed 1,810 g. There was a cortical defect about $2 \mathrm{~cm}$ across in the vertex of the left parietal lobe.

On the undersurface of the right occipital lobe there was an area of cortical softening some $3 \mathrm{~cm}$ in diameter. There was patchy haemorrhagic infarction in the 'watershed areas' of the right frontal, the left frontal, and both occipital lobes. The right globus pallidus was infarcted. Haemorrhagic infarction was also found in the cerebellar hemispheres. The right inferior olive was greatly enlarged (Fig. 12).

MICROSCOPICAL EXAMINATION In addition to the gross haemorrhage, foci of complete or partial cortical necrosis were scattered throughout both hemispheres, mostly in

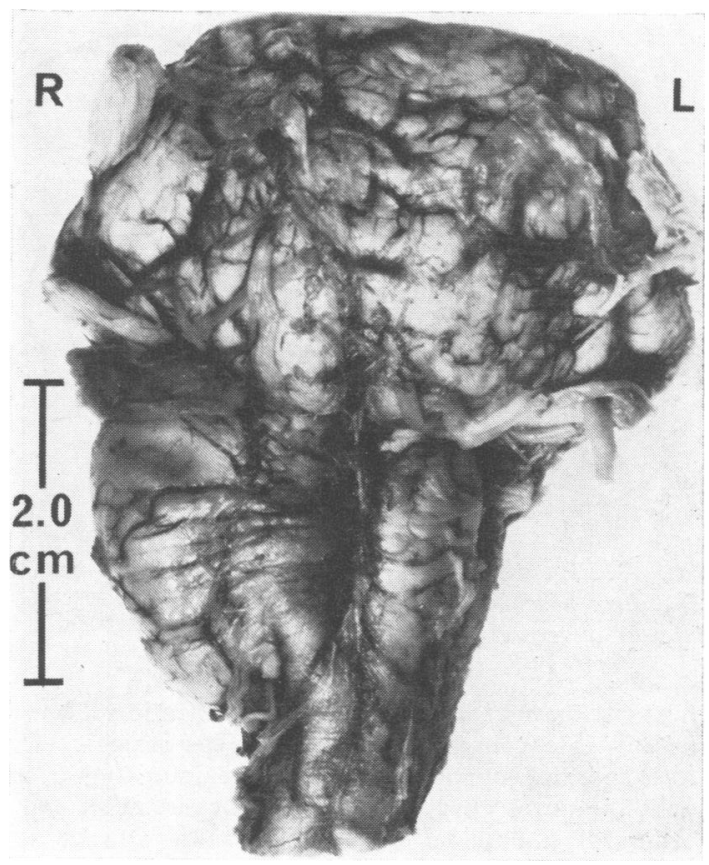

FIG. 12. Case 4. Anterior view of brain-stem showing hypertrophy of the right inferior olive.

the 'watershed' areas. Loss of Purkinje cells in the cerebellum was marked. In the parietal lobe large ballooned and contorted neurones were scattered through the cortex adjacent to the site of the previous gyrectomy. Giant abnormal astrocytes were also present in the underlying white matter. Demyelination and marked fibrous gliosis were found in the immediate area of the scar. No further vascular malformation was detected similar to the one that had previously been removed.

No further collections of anomalous cells were found elsewhere in the hemispheres or in the brain-stem apart from the right inferior olive. This was grossly enlarged compared with the unaffected olive on the opposite side (Fig. 13). It contained a tangled mass of abnormal neurones and severe fibrosis with glial and other cells, often multinucleate, which were of uncertain origin. The bizarre cells spread inferomedially into the right pyramidal tract. No other long-standing lesion in the hind brain was found.

\section{CASE 5}

M.1708: R.H. $97 / 69$ This man had a right anterior temporal lobectomy at the age of 20 years, followed eight years later by a right frontal lobectomy.

There was no family history of mental disorder; a paternal uncle suffered from cryptogenic epilepsy. The patient's birth was normal. Fits began when he was 13 years old, the first occurring 24 hours after an accident 


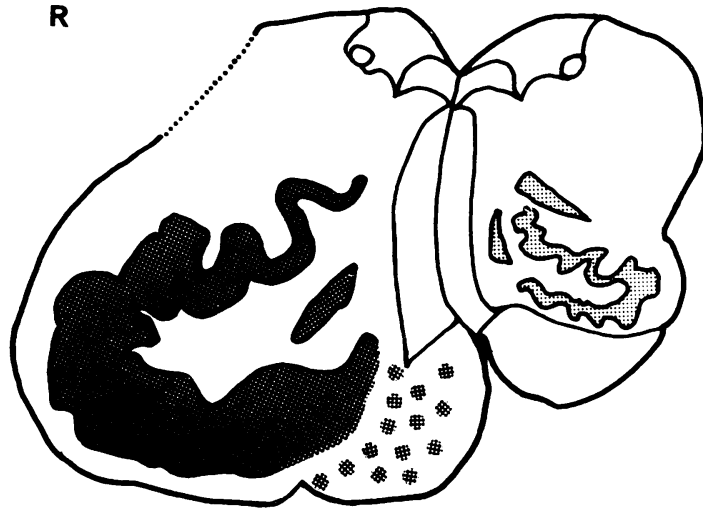

FIG. 13. Case 4. Outline of coronal cut through medulla. The dark hatching shows the affected areas in the right inferior olive and in the adjacent pyramid.

in which his right forehead was struck by a lorry, but he did not lose consciousness. Initially his major attacks were heralded by ringing in the ears, but after a few years the auras changed to a cephalic sensation and a feeling of abdominal distension. Minor attacks also occurred occasionally.

No physical or radiological abnormality was found before operation. The WBI Full Scale and Performance Scale assessments were both 95 . The Verbal Scale was 96. EEG studies showed generalized dysrhythmia with almost continuous slow and intermittent fast activity centred over the right fronto-temporal area. Some spiking was picked up from the right sphenoidal electrode but this was more prominent over the anterior temporal and inferior frontal regions. The electrocorticogram indicated a temporal origin of the spikes and the right temporal lobe was therefore removed. This looked and felt normal at operation. Fits occurred occasionally during the next five years. After a fit-free period of two years, they became more frequent and he would have up to 10 by day and by night. In a typical attack the patient would grimace and growl, his legs would become stiff, and he would raise his arms above his shoulders. There was now no remembered aura. He lost his job and became depressed and solitary.

When he was readmitted eight years after the temporal lobectomy, the EEG and electrocorticographic recordings showed frequent spikes and sharp waves arising in the right inferior frontal region. The anterior part of the right frontal lobe was therefore resected including the whole of its orbital surface. The tissue looked and felt normal. For 18 months after this second operation he has been free of seizures and at work. He does, however, complain of frequent but momentary sensations of pressure in his head similar to the preoperative auras, without lapses of consciousness. An EEG record made a year after the frontal lobectomy showed some sharp waves in the right fronto-temporo-parietal regions.

PATHOLOGICAL EXAMINATION The first specimen con- sisted of the right temporal lobe, including most of the cortex and white matter of the three temporal gyri, the fusiform and parahippocampal gyri, and the hippocampus. A fragment of the amygdaloid nucleus was also present. No macroscopic or microscopic abnormality was found.

The second specimen consisted of the anterior portion of the right frontal lobe measuring $3.5 \mathrm{~cm}$ anteroposteriorly from the frontal convexity (Fig. 14). Sagittal sections showed extensive intracortical and subcortical haemorrhage but no other abnormality. Under the microscope, however, a single area of cortex, measuring some $4 \mathrm{~cm}$ above-down $\times 3.0 \mathrm{~cm}$ horizontally, showed many large abnormal nerve cells scattered throughout all layers except the first. These cells were similar to those described in preceding cases (Fig. 15a, b; Fig. 16b) and were high-lighted selectively in silver impregnations. Serial sections showed that the cortical abnormality was confined mainly to the infero-lateral aspect of the frontal convexity.

The subcortical white matter was moderately gliotic and in some areas contained monstrous, bizarre, astrocytes with large dark nuclei and opalescent cytoplasm (Fig. 16a).

\section{CASE 6}

M. 1325 A right anterior temporal lobectomy was per formed on this patient when he was 28 .

He was the second in a sibship of six but his mothe had had two miscarriages and a set of triplets had diet in the neonatal period. His own birth and early develop ment were normal until the age of 3 when he suffere bilateral otitis media. Soon afterwards he had two or thre

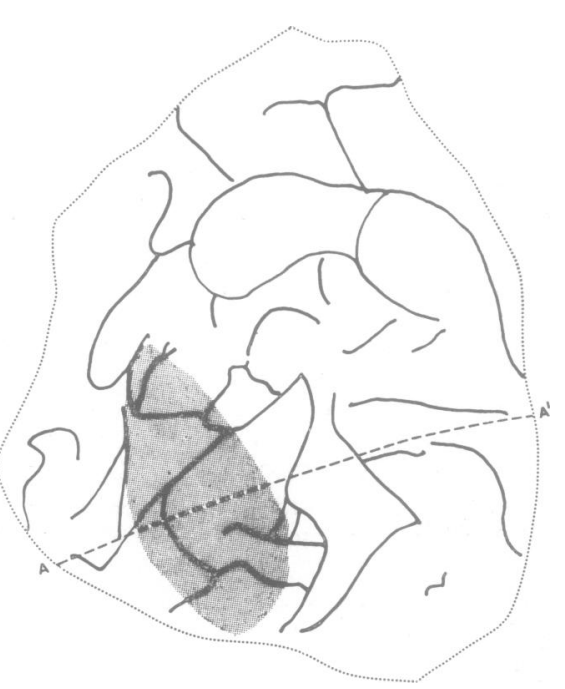

FIG. 14. Case 5. Outline of resected right frontal pole. The affected area lies in the anterolateral convexity and across the orbitofrontal junction $\left(A A^{\prime}\right)$. 


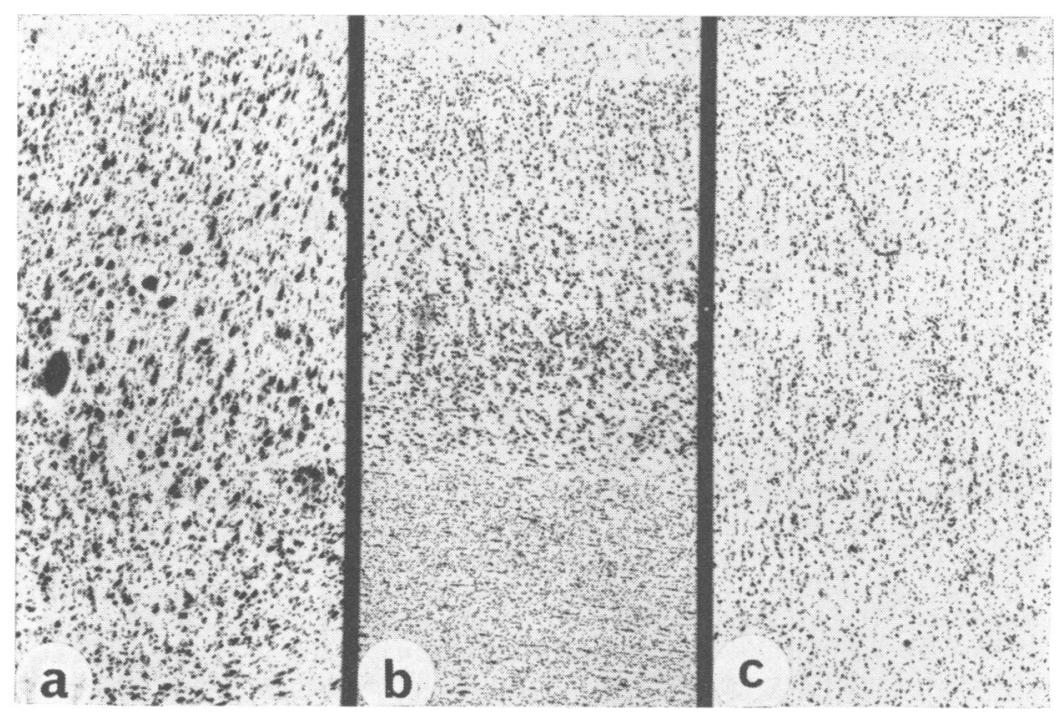

FIG. 15. a. Affected cortex riddled with giant neurones in case 5. Compare with: b. normal cortex, c. the appearance of a typical tuber in a known case of tuberous sclerosis $(R . H .28 / 65)$. The cortex is greatly widened both in a and in $\mathrm{c}$ but the neuronal population is strikingly different. Cresyl violet, $a, b$, and $c \times 30$.

sudden attacks of sleepiness which were ascribed to petit mal.

At the age of 7 he was seriously burned by electrocution and was thought to be dead. Major fits began at the age of 9 . In the early attacks he flushed, shook, stared, then went white and recovered. In the years before operation he had regular nocturnal convulsions with diurnal psychomotor attacks which were heralded by 'a feeling like taking an anaesthetic while climbing a spiral stair- case looking upwards towards the light at the top'.

His mental state was normal, and he was regularly employed as a colour-matcher. Preoperatively his IQs (WBI) were Verbal Scale 111, Performance Scale 106, Full Scale 110. Physical examination revealed extensive scarring due to burns but no abnormal neurological signs. The fundi were normal.

Radiography of the skull showed some asymmetry but without lateralizing signs. The pneumoencephalo-

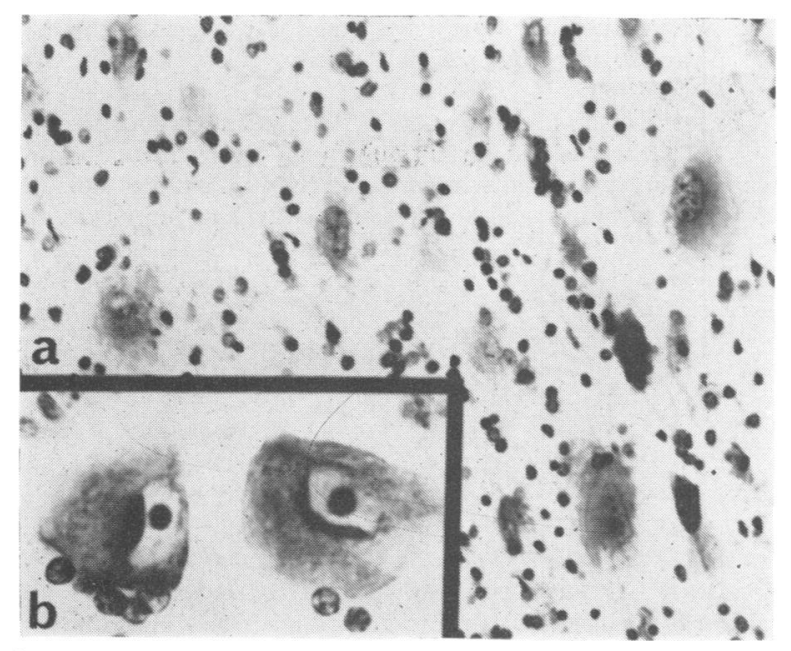

FIG. 16. Case 5. a. Abnormal glia in depths of lesion. b. Inset shows two giant neurones from the same case with crescentic thickening of the nuclear rim. (This is thought not to be an artefact.) Cresyl violet, $a, \times 250 ; b, \times 620$. 
gram showed slight dilatation of the right lateral ventricle. Frequently recurring focal spike discharges in the right anterior temporal region were seen in EEG recordings while awake and during sleep induced by thiopentone.

At operation the temporal lobe looked normal but the superior part of the specimen felt unusually firm. Electrocorticography showed rhythmic sharp waves over the rostral convexity and an anterior temporal lobectomy was performed.

He was last seen five years after the operation. He had experienced about five psychomotor attacks in that period. He was regularly employed and socially active. He married and emigrated; 10 years after operation he writes that he still has one or two seizures a year which are precipitated by emotion. He has two jobs and supports four stepchildren. An EEG recording taken a year after operation showed an occasional sharp component in the right posterior temporal region.

PATHOLOGICAL EXAMINATION The specimen consisted of the anterior $6.0 \mathrm{~cm}$ of the right temporal lobe and extended in coronal section from the superior temporal gyrus laterally to the medial edge of the hippocampus (Fig. 17).

No abnormality of the leptomeninges or of the cortical surface was noted but a coronal cut showed that the junction between the cortex and white matter of the inferior temporal gyrus and the fusiform gyrus was blurred.

In these areas the cortical lamination was broken up by the presence of many large, bizarre nerve cells combined with the relative lack of a normal neuronal population. The atypical cells stained deeply, resembling those described in case 1 . In the deeper cortical layers and in the subjacent white matter, large, distorted, ballooned cells with clear nuclei and opalescent cytoplasm were present. The white matter in these areas was poorly myelinated and a few perivascular fat phagocytes were seen. No dense fibrous gliosis could be demonstrated and no glial 'wheatsheaves' were seen. The hippocampus

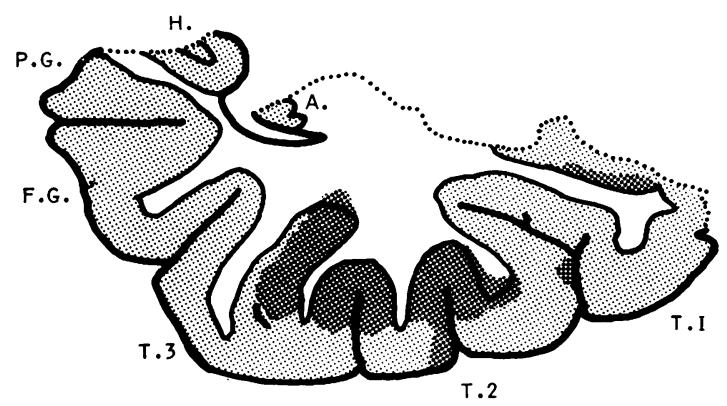

FIG. 17. Case 6. The limits of the affected cortex and subjacent white matter in the right temporal lobe. $(T 1,2,3$, the three temporal gyri; F.G. fusiform gyrus; P.H. parahippocampal gyrus; H. hippocampus; A. amygdaloid nucleus.) and a small part of the amygdaloid nucleus were present $Z$ and appeared normal.

CASE 7

M.44/55 This man underwent a left temporal lobectomy ${ }^{\top}$ when 46 years old. Little was known of his birth and early development. One sister was educationally subnormal but there was no history of epilepsy or of other mental disorder in the family.

The patient had lived a normal life working as a master $\vec{\overline{ }}$ plumber until the onset of epilepsy at the age of 31 . In $\stackrel{5}{+}$ the first attack he fell to the floor while drying dishes and $\bar{C}$ lay unconscious for three to four minutes. He was unaware of any warning of this or of any subsequent $\frac{\bar{s}}{T}$ episode. A year later regular attacks started in which he would smile, rub his hands, and then perform a complex automatism. No drug régime affected the fre- $\infty$ quency of these fits, which occurred about twice a week. $\overrightarrow{0}$ While in the neurosurgical unit, he had several psycho- $\overrightarrow{-}$ motor attacks with only vague recollection of his subse- $\vec{\omega}$ quent automatic behaviour.

His mental state was normal but he complained that his memory and concentration were so poor that he had? recently given up his own business and become an $\underset{+}{\omega}$ employed plumber. Preoperatively his measurements (WBI) were Verbal Scale 93, Performance Scale $8, \omega$ Full Scale 94.

No neurological or other abnormality was found physical examination. The pneumoencephalogram w@ normal, except that the left inferior horn could not $\overline{\text { Ke }}$ filled. In the EEG recordings a spike discharging focuss was identified at the left sphenoidal electrode whith $\frac{\bar{C}}{\infty}$ spread at times to the left inferior frontal region. right-sided abnormal activity was seen.

A left anterior temporal lobectomy was carried out. At operation the lobe looked and felt normal.

The patient was last seen 15 years after the operation. Fleeting 'turns' had occurred occasionally but other kinds of epileptic attacks had ceased. Radiography $\bar{O}$ revealed a faint 'calcified shadow' deep in the left parietal lobe. The EEG continued to be abnormal with reduced $\stackrel{\square}{\varrho}$ alpha activity, slow activity, and sharp waves in the le $\mathrm{f}_{\mathrm{t}} \overrightarrow{\mathrm{F}}$ posterior temporal region.

PATHOLOGICAL EXAMINATION The specimen consisted of the left uncus, the parahippocampal, the fusiform and the inferior and middle temporal gyri with fragments of the amygdaloid nucleus and the anterior hippocampus $\overrightarrow{0}$ (Fig. 18).

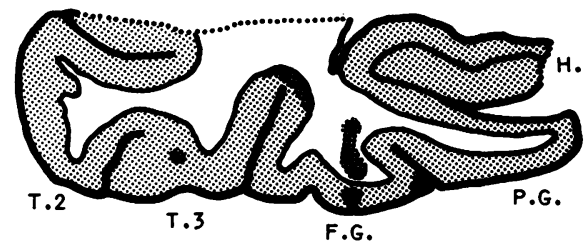

FIG. 18. Case 7. Outline of resected specimen-the $\mathbb{O}$ patches of abnormal cortex in the left temporal lobe are N darkly shaded. 
No naked eye abnormality was found but microscopy of the cerebral cortex revealed a spattering of large abnormal neurones, the bodies and processes of which impregnated deeply with silver. A few isolated malformed and often monstrous glial cells were scattered through the white matter. In particular, the white matter deep to the cortex around the collateral sulcus contained a small poorly myelinated patch in which numerous grossly abnormal cells were seen. These cells, with their opalescent cytoplasm and large deeply stained and sometimes multiple nuclei, resembled those seen in the other cases (Fig. 19a, b).

\section{CASE 8}

R.H. 13/65 This man was aged 17 when he underwent a left anterior temporal lobectomy.

His mother had valvular disease of the heart and was in an oxygen tent at the time of his birth. He weighed $7 \frac{1}{2} \mathrm{lb}(3.4 \mathrm{~kg})$ but no other details are known. There was one older healthy sibling and no family history of epilepsy. The patient progressed normally until the onset of epilepsy at 14 years. The initial attack was a convulsion while asleep followed by similar attacks for the next four nights. He was given anticonvulsant drugs and subsequent attacks occurred at one to three monthly intervals, always at night. He became aggressive and difficult and was admitted to a mental hospital for six months. He was first referred for surgical treatment two years before operation, but this was deferred because his behaviour had improved and the seizures had been purely nocturnal. However. six months later he developed numerous diurnal attacks in which he would become suddenly unresponsive and aggressive. No aura was recalled.

Preoperative IQ (WBI) assessment showed a Verbal Scale 73, Performance Scale 82, and Full Scale 73. No neurological or other abnormality was found on physical examination and none of the stigmata of tuberous sclerosis was identified.

Radiography of the skull revealed minor asymmetries; a pneumoencephalogram showed slight dilatation of the left anterior horn. The EEG recordings showed frequent clusters of sharp slow complexes widely distributed but always appearing to originate in the left temporal region. High voltage sharp waves were maximal in the left sphenoidal lead.

At operation the left temporal pole appeared truncated and a small subcortical bluish area $5.0 \mathrm{~mm}$ in diameter was evident about $2.0 \mathrm{~cm}$ behind the pole in the middle temporal gyrus. (No histological explanation of this was found.) A $6.0 \mathrm{~cm}$ anterior temporal lobectomy was performed, much of its hippocampus being removed by suction.

In the immediate postoperative period the patient became fiercely aggressive and needed restraint in a closed ward. Infrequent epileptic attacks have continued since the operation five years ago. His aggressive outbursts are fewer but he has a poor work record. A sphenoidal EEG study under thiopentone narcosis performed a year after operation showed, in addition to prominent sharp waves in the left posterior temporal region, frequent sharp waves and spike discharges on the opposite side, some of which reversed phase at the right sphenoidal electrode. These right-sided discharges had been inconspicuous before operation. The presence of this epileptic focus in the opposite temporal lobe suggests that a structural abnormality may also be present on this side.

PATHOLOGICAL EXAMINATION The resected left temporal lobe extended from the middle temporal gyrus to the crown of the parahippocampal gyrus. No hippocampus or amygdaloid nucleus was identified (Fig. 20). No macroscopic abnormality was found.

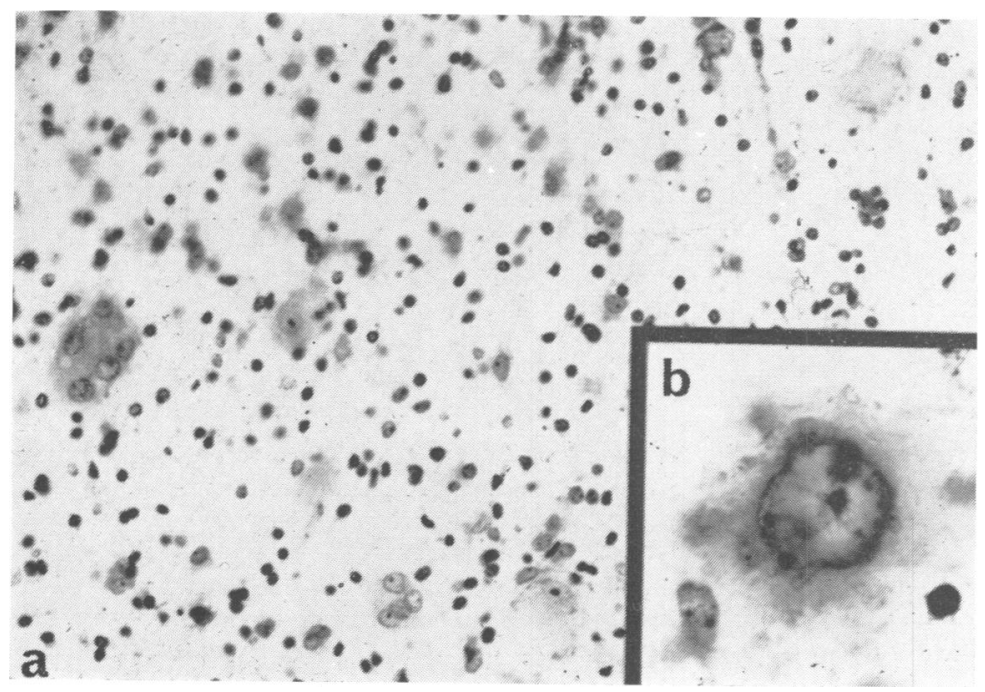

FIG. 19. Case 7. Abnormal cells in white matter of fusiform gyrus. Cresyl violet, $a, \times 160 ; b, \times 480$. 


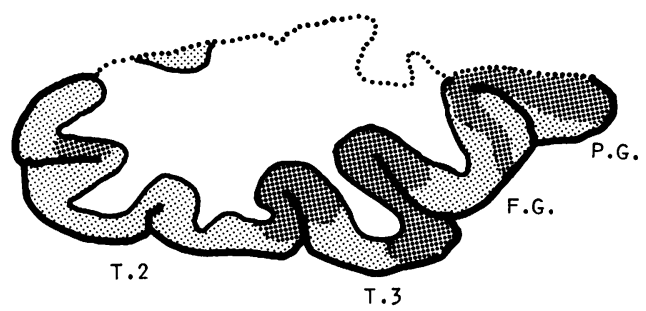

FIG. 20. Case 8. Scattered areas of abnormal cortex in the resected temporal lobe are darkly shaded.

Histological study showed the architecture of the cortex, particularly round the base of most sulci, to be disturbed by the presence of many abnormally large, deeply staining nerve cells (Fig. 21a, b). These were most noticeable in the third layer but were also scattered in the other layers. The large cells and their processes impregnated deeply and selectively with silver.

An increase of astrocytic nuclei was also noticeable particularly in the molecular layer and also in the deeper cortical layers. Fibrous gliosis was slight; no 'wheatsheaving' along the sub-pial surface was seen.

\section{CASE 9}

R.H. 42/68 A boy who had developed temporal lobe epilepsy at the age of 12 was 17 years old at the time of a left anterior temporal lobectomy.
The patient's birth and early development were normal. $\underset{\mathbb{D}}{Z}$ There was no family history of epilepsy or of mental $\stackrel{\mathbb{D}}{=}$ disorder. Ictal experiences began at the age of 12 when

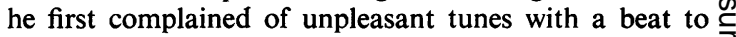
them running through his head. They were associated $\hat{\theta}$ with a 'shivering feeling' in the legs which passed up into $D$ the epigastrium. By the age of 14 'absences', in which he

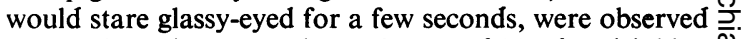
two or three times a week. At the age of 15 , after drinking alcohol, he had a series of convulsions. Subsequently. the aura of tunes 'not like ordinary music' would occur $\overrightarrow{\vec{F}}$ several times a day, often being followed by a convulsive $\stackrel{\mathcal{P}}{+}$ attack lasting up to half an hour. The seizures were followed by dysphasia. His memory deteriorated and he $\underline{\underline{D}}$ became aggressive. He was unable to work and twice $\frac{\bar{\omega}}{2}$ attempted suicide. His IQ levels before operation (WBI) $\mathbb{D}$ were Verbal Scale 115, Performance Scale 104, Full Scale 111. There was a slight auditory verbal learning deficit.

Apart from a moderate nominal dysphasia no neuro- $\overrightarrow{0}$ logical or other abnormality was found. Radiographs of the skull were normal; a pneumoencephalogram $\vec{\omega}$ revealed slight dilatation of the left temporal horn. EEG recordings, including studies with sphenoidal electrodes under thiopentone, revealed active spike discharges in the left temporal electrodes and occasional spiking at the $\underset{\oplus}{\dot{A}}$ right sphenoidal electrode. A $6 \mathrm{~cm}$ anterior temporal lobectomy was performed.

At operation the surface of the brain appeared norma․ Electrocorticography showed spike discharges principalig, 윽 at the left temporal pole and at the uncal electrode; stimulation of the amygdalar electrode was followed a typical seizure.

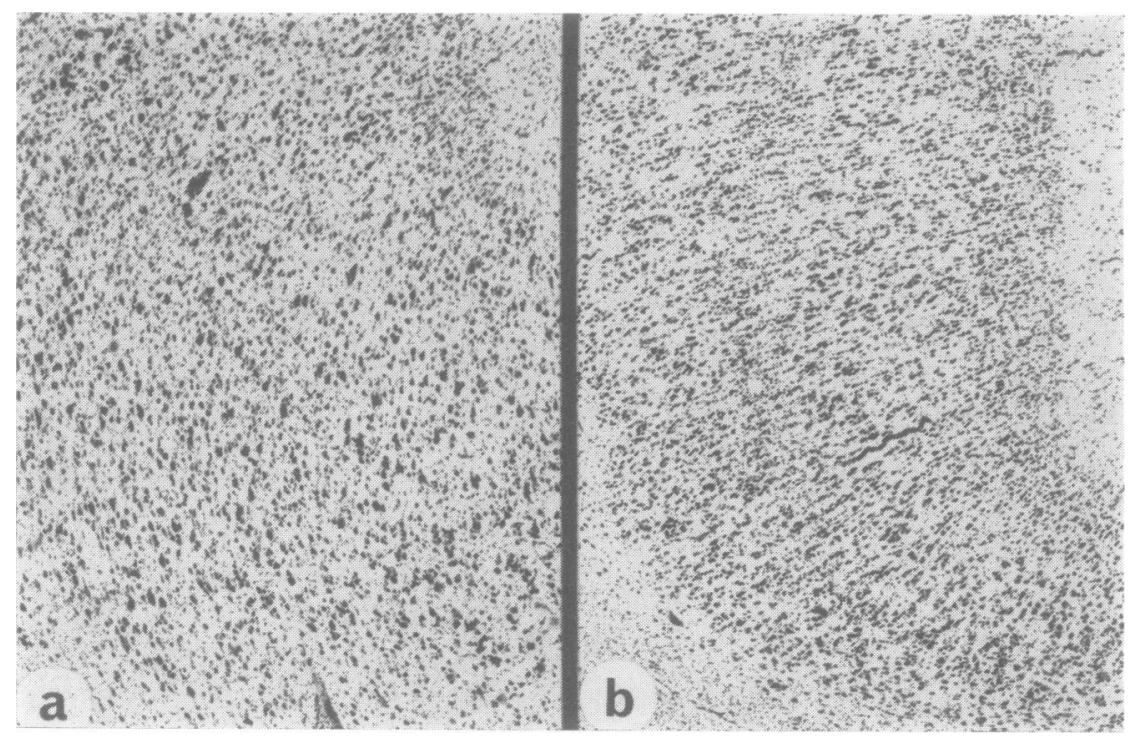

FIG. 21. a. Area of cortex from case 8 showing an abnormal population of large neurones with loss of lamination, for comparison with: b. the same gyrus in another lobectomy specimen (M2923) removed from a patient without this type of dysplastic cortex. Cresyl violet, $a$ and $b$ $\times 30$. 
Postoperatively his relationship with his family has continued to be grossly disturbed. Often aggressive at home, each time he would settle down in hospital. Two years after operation he was reported to be free from fits, although he may have had nocturnal attacks during the year after operation. The auras had ceased. He has been working as a petrol pump attendant and he is recently reported to have applied for a driving licence. The EEG no longer showed spiking or fast wave discharges.

PATHOLOGICAL EXAMINATION The fixed specimen measured $6.0 \mathrm{~cm}$ anteroposteriorly and $6.0 \mathrm{~cm}$ across its coronal face.

The superolateral border of the specimen included the dorsal part of the superior temporal gyrus. The anterior hippocampus formed its medial border and all the intervening gyri were present. A fragment of the amygdaloid nucleus was also included.

No macroscopic abnormality was found. The microscopic anomaly was restricted to a circumscribed area of cortex in the anterior part of the superior temporal gyrus (Fig. 22). In this area, which measured roughly $1.0 \mathrm{~cm}$ across, many huge disorientated neurones were scattered through all the cortical layers except the first (Figs. 23, 24). The cells were similar to those seen in all the other cases, and, like them, impregnated deeply with silver. Serial sections were cut and stained at frequent intervals but no similar neuronal anomaly was found elsewhere in the specimen. No glial abnormality was detected.

\section{CASE 10}

R.H. 22/67 This man was aged 17 when he underwent a left temporal lobectomy (Mr. A. Hulme).

He had been an in-patient in a hospital for the mentally

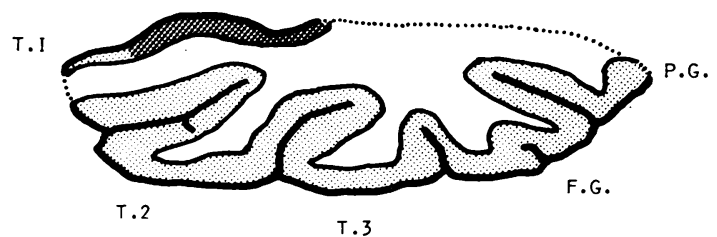

FIG. 22. Case 9. Outline of resected temporal lobe. The dark hatching indicates a population of abnormally large neurones confined to the superior temporal gyrus (TI).

subnormal from the age of 4 years. Little was known of his early development. Seizures of unknown cause started at the age of 2 years and usually affected the right side of the body more than the left. The boy's behaviour deteriorated and by the age of 4 he was considered unmanageable. He was given to impulsive rages and wild behaviour; he was immature and backward. Convulsions, interspersed with aggressive outbursts and sexual misdemeanours, continued unabated up to the time of operation.

Before operation plain radiographs of the skull had revealed no abnormality. Extensive EEG studies, including recording from sphenoidal electrodes, had suggested a focus of abnormal tissue lying deep in the left posterior temporal or the inferior parieto-occipital region, although abnormal activity involved the whole of the left hemisphere (Dr. H. J. Crow). Preoperative IQ assessments (WAIS) were Verbal Scale 50, Performance Scale 57, Full Scale 48.

At operation the cortical surface of the left temporal lobe was apparently normal but electrocorticography indicated a widespread abnormality maximal in the middle of the superior temporal gyrus. The lobe was removed.

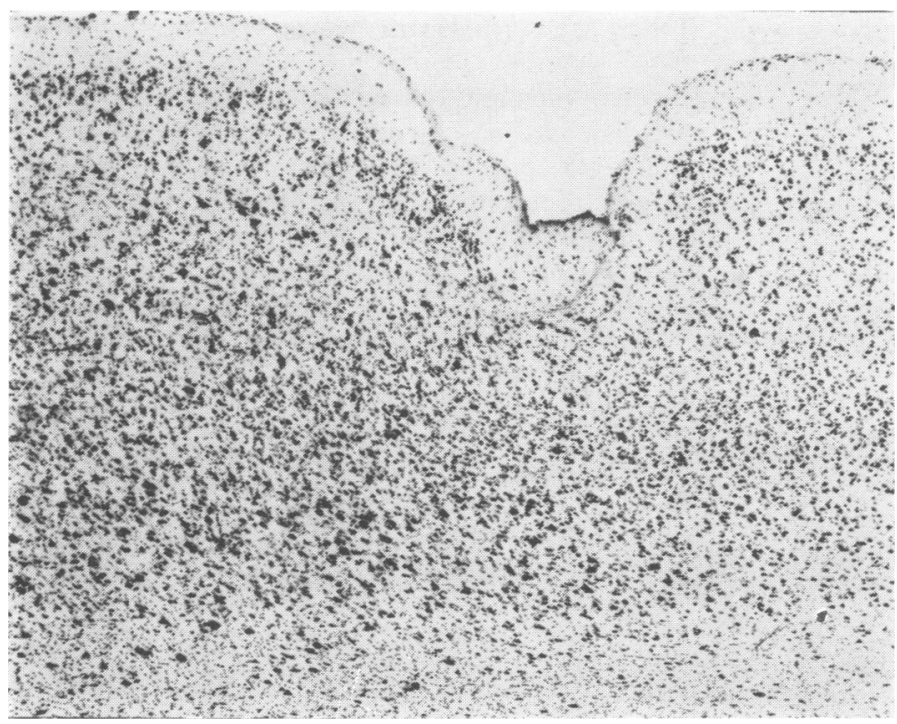

FIG. 23. Case 9. Cortex on the right of the field looks normal until anomalous neurones start to build up below a dip in the cortical surface. The molecular layer remains unaffected. Cresyl violet, $\times 30$. 




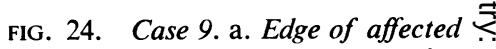
cortex. b. Severely affected area of cortex. Cresyl violet, a $\times 40$; $b \times 50$.

He has remained in hospital since the operation and has continued to have seizures, although these were reported to be better controlled. There were no signs suggestive of tuberous sclerosis, though the patient had suffered an extensive acne-form eruption.

PATHOLOGICAL EXAMINATION Sections of the specimen were made available through the kindness of the late Dr. Ronald Norman and Dr. Sheila Sandry. The full coronal extent of the temporal lobe was present with the exception of the dorsal part of the hippocampus (Fig. 25). The cortex between the inferior temporal and the fusiform gyrus contained, to quote Dr. Norman's report, large numbers of giant neurones about the size of the giant cells of Betz. These cells had nuclei of neuronal type and coarse Nissl bodies. They occurred in all the cortical layers and were either interspersed with nerve cells of normal size or more commonly were the only or the chief constituent of the grey matter. The celfs. were not present in all the levels of the lobe that wep $\overrightarrow{0}$ sampled but the focus of abnormality was at least 2.7 $\mathrm{cm}$ long and mainly involved the cortex around a single sulcus. No gliosis was found.

\section{DISCUSSION}

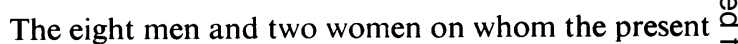
study is based had all suifered for many years from $\overrightarrow{\overrightarrow{0}}$ intractable epilepsy. The clinical and, in particular, 3 the electroencephalographic findings had pointed to a predominantly unilateral focal disorder, and the area of brain thought to be implicated had been removed surgically. In all cases the cortical surface

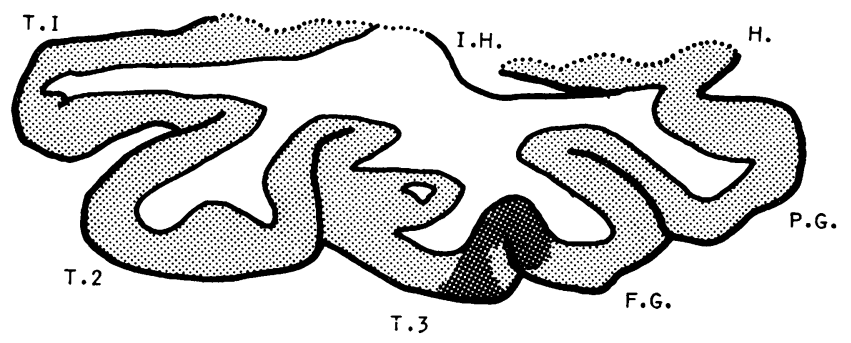

FIG. 25. Case 10. Dark hatching shows the site of abnormally large neurones lying between the inferior temporal and the fusiform gyri. 
of the fixed lobe or tissue appeared normal to the naked eye, and in seven of the 10 specimens there was nothing remarkable about the cut surfaces. In the remaining three, the cortical ribbon of one or more gyri, although of normal colour, was wider than expected and its junction with the white matter was blurred.

The most striking microscopic feature at low power was the localized disruption of the normal cortical lamination by an excess of large aberrant neurones scattered randomly through all but the first layer. Such an area might occur at any point along or round a gyrus, but any one patch seldom stretched horizontally through the cortical ribbon for more than about $2.0 \mathrm{~cm}$. The discrete involvement of the striate area (in coronal section) in the first case was the most extensive lesion found; at the other extreme, in case 7 , only occasional giant malformed neurones were seen. The aberrant nerve cells stood out partly because of their numbers and their inappropriate size, which at times approached that of a giant Betz cell (Fig. 8a, b), and partly because of their bizarre structure. Mainly pyramidal in shape, they pointed in all directions and were at times crowded together. At higher power one or more segments of the nuclear rim often showed a curious elliptical thickening (Fig. 16b). The Nissl substance, particularly that adjacent to the nucleus, tended to be unusually dense and to have a wild, tigroid appearance (Fig. 8b). The bodies and processes of these anomalous neurones stood out in the appropriate silver stains because of their intense and selective impregnation. The most characteristic feature, therefore, was the disorganization both of the cortical architecture and of many of its individual neurones. In seven of the 10 cases the anarchy was aggravated by the addition of malformed cells of uncertain origin with large, sometimes multiple, nuclei surrounded by an excess of opalescent, pseudopodic cytoplasm. These groteque forms were concentrated in the deeper layers of the disorganized cortex and in the underlying white matter (Fig. 4a). Very occasionally clusters of such cells were seen apparently detached from the cortex and lying towards the centrum semi-ovale. In several cases marked proliferation of large amoeba-like astrocytes had occurred in the molecular layer overlying the disordered, but not the normal, cortex.

The affected and, to a lesser extent, the unaffected areas sometimes showed an increase in reactive but otherwise normal astrocytes. Fibrous gliosis was nowhere marked; there was sometimes a mild reduction of myelinated fibres in the white matter deep to the abnormal cortex. Cyst formation and all forms of calcification were absent in all cases.

No reports of closely similar observations have been traced. The findings, however, do bring to mind Crome's description (1957) of three severely retarded epileptic infants. From one of these a cerebral biopsy had been taken, in which giant nerve cells were found scattered through areas of atrophic and gliotic cortex. The condition was thought to be congenital and a slight resemblance to tuberous sclerosis was mentioned. A fourth idiot child dying with epilepsy was reported by Berg and Crome in 1960. In this patient, one temporal lobe was found to be peculiarly hard and to contain many large disorientated neurones. On these, as well as on clinical and other neurohistological grounds, the possibility of tuberous sclerosis was more seriously considered than in the first report, but less precise terms like 'phakomatosis' or 'neurocutaneous dysplasia' were preferred. In a similar study, Cravioto and Feigin (1960) described an epileptic, subnormal girl of 21 in part of whose brain the cortical architecture was disrupted by abnormal cells. They cautiously entitled this 'localized cerebral gliosis with giant neurons histologically resembling tuberous sclerosis'.

During the last 10 years there have been several pathological studies on cerebral tissue resected from patients known to have tuberous sclerosis. Some of these reports have been concerned, not with the cortical tubers, but with the surgical treatment of the intraventricular neoplasms that often occur in this condition (Obrador, 1963; Kapp, Paulson, and Odom, 1967, and for other references). In 1965, however, Perier and Achslogh described a mentally subnormal patient on whom they had operated for focal epilepsy. In the resected tissue from the parietal lobe many bizarre neurones and glia were found, Tuberous sclerosis was diagnosed but it was emphasised that no other evidence of this condition was found. In the following year Perot, Weir, and Rasmussen reported on gyrectomies carried out on seven epileptic patients. The histological changes were summarily described as those of tuberous sclerosis. Four of the seven patients had other evidence of the condition, including two with facial lesions and two with intracerebral calcification. Three were mencally retarded; all had developed fits by the age of 7 .

The neurohistological abncrmalities in the present cases are also reminiscent of tuberous sclerosis, but when they are compared closely with the typical tuber, material differences can be seen that make this diagnosis difficult to accept, particularly when the clinical evidence is taken into account. Firstly, although occasional features such as an isolated fibroma or scattered naevi were found in two patients, none of the 10 showed any of the classical cutaneous or somatic stigmata of this disease. Secondly, 
pneumoencephalograms gave no indication of 'candle-guttering' in any case, while radiological evidence of intracerebral calcification was absent in nine cases and only faintly suggested in the tenth. Thirdly, none of the patients had a family history of this condition; only three had an epileptic relative and in only one family was a mentally subnormal member identified. Fourthly, although the onset of fits in tuberous sclerosis may be at almost any age and has been recorded in the early 50s (Gupta, 1956), they usually start in the first two years of life (Critchley and Earl, 1932). In contrast, the mean age at onset in the present cases was 12 , with only two starting under the age of 3 , and the rest ranging between 7 and 31. Fifthly, although the intelligence quotient of three of the present patients was low, in three others it approached 100 and in four it exceeded this figure.

This lack of so many of the remarkably distinctive features of tuberous sclerosis may, however, not rule out the condition, particularly as formes frustes are known to occur occasionally and may even be considerably more common than is generally recognized (Pampiglione, Evans, Harris, and Moynahan, 1968).

The most striking difference is seen when the neuropathological lesions are compared with the typical tuber. Thus no macroscopic abnormality could be found on the surface of any of the fixed specimens and it was only after they had been sliced that the margin between cortex and white matter was found to be blurred in three cases. The remaining seven appeared normal. The histological picture, taken as a whole, was equally unlike that of the classical tuber within the cortex. The present cases showed masses of large aberrant neurones littered apparently in chaos through all but the first molecular layer, whereas, although it is not always appreciated, the cortex of the true tuber stands out as pale and poorly stained (Fig. 15a, b, c) because is is so poorly populated. It is the monstrosity of some of the nerve cells in tuberous sclerosis and not the number of them that is so striking (Hallervorden and Krücke, 1956). The glial reaction also differed radically. In three cases bizarre cell forms at the corticomedullary junction were absent, and there was none of the tuber's typical 'wheatsheaves', 'crossed swords', or 'tangled hair' (Critchley and Earl, 1932) in the subpial region in any specimen. Again, calcification and cyst formation, either of which may be seen in the classical tuber, were never identified.

The most crucial question, however, concerns the multiplicity of lesions. Tuberous sclerosis has a broad spectrum during life, ranging from the clinically silent, through the protean formes frustes, to the full-blown epiloia. In contrast, the neuropathological picture is remarkably stereotyped. One of its more constant features is the way in which the lesions are distributed through the cerebral hemispheres, and the brain with a single tuber is excessively rare (Jakob, 1914; Yakovlev, 1939). It is, therefore, important to know whether a similar dissemination of lesions, beyond the operative site, had occurred in the present cases.

The evidence from the one patient who has died is equivocal for, although only the single cortical lesion was found, there was gross malformation in the lower brain-stem. This inexplicable olivary hypertrophy was not unlike a tuber histologically but was atypical in the sense that no record of a similar mass in tuberous sclerosis has been traced. The evidence obtained from the nine living patients is also conflicting largely because it is incomplete. The part of the brain to be resected in each case was centred on the area of maximal electrical abnormality and it was mainly because of this preliminary EEG localization that the zones of dysplastic cortex came to be recognized. There is some reason, therefore, to suspect that the operation had removed the main, if not the only, lesion, particularly as most of the patients have suffered considerably less from the epilepsy since the operation and in a few the fie 웅 have not recurred (Table). Nevertheless, it mas. well be that other, if less ostentatious, areas cortical dysplasia have been left behind. This possi bility is supported by the fact that even within the limits of the resected lobes the abnormality we sometimes disseminated rather than confined to single patch. The degree, therefore, to which the brain as a whole may be affected remains uncertain. It will probably vary greatly from one case to another but it could scarcely be as extensive as that commonly seen in tuberous sclerosis.

If each of the points is considered separately, there $\stackrel{\mathbb{Q}}{\unrhd}$ is clearly no single clinical or neuropathological $\overrightarrow{\overrightarrow{0}}$ feature which distinguishes absolutely the present 3 cases from tuberous sclerosis. A combination of the various differences, however, taken together with the considerable similarities between the members of the present series, suggests that they fall into a category of their own. As a group they are distinct from conditions such as pachygyria (Crome, 1956) and multiple neurofibromatosis in which Rosman 8 and Pearce (1967) have found a variety of cortical anomalies. There is no good evidence that the foci 응 of abnormal tissue are the consequence of infection or of trauma, although in three patients (cases $2,3,5$ ) $\frac{\text { O }}{2}$ the first attacks may have been triggered off by a head injury. While clinically similar in the way they $N$ present, the lesions are also distinct histologically 0 from the 'small tumours of the temporal lobe' N encountered by Cavanagh in 1958 and seen sporadic- 
ally by the present writers since then. It would moreover, be misleading, not only because of their appearance, but also because of their behaviour, to classify them as tumours of any other kind. Even the term hamartoma, which implies a tumour-like malformation, seems inappropriate for something that often appears to be little more than an architectural folly. That is to say, the developmental flaw, or 'hamartia', is there but the extension into being tumour-like, or 'hamartomatous', is not.

For the present, therefore, it would seem best to look on these abnormalities as a particular form of localized cortical dysplasia in which anomalous populations of neurones, and often of glia, underlie the electrical and clinical manifestations of certain focal forms of epilepsy. It is conceivable that they may eventually prove to be linked to tuberous sclerosis or the phakomatoses, but the available evidence suggests that this relationship is remote, if it exists at all.

We are very grateful to Dr. M. Driver for his collaboration on the electroencephalographic side. Many other colleagues have cooperated most generously. We would like to thank in particular Professor Peter Daniel and his colleagues in the Department of Neuropathology, Institute of Psychiatry, London; Mr. J. Andrew and Mr. A. Hulme generously allowed us to include in the study their patients, case 2 and case 10 respectively. Dr. Taylor was supported during the work by a grant from the Board of Governors of Guy's, Bethlem Royal, and Maudsley Hospitals, and a grant given to the Human Development Research Unit by the Department of Education and Science, the Department of Employment and Productivity, and the Wolfson Foundation. The work was also helped by a grant to Dr. Corsellis from the Medical Research Council.

\section{REFERENCES}

Berg, J. M., and Crome, L. (1960). A possible case of atypical tuberose sclerosis. J. ment. Defic. Res., 4, 24-31.
Cavanagh, J. B. (1958). On certain small tumours encountered in the temporal lobe. Brain, 81, 389-405.

Cravioto, H., and Feigin, I. (1960). Localized cerebral gliosis with giant neurons histologically resembling tuberous sclerosis. J. Neuropath. exp. Neurol., 19, 572-579.

Critchley, M., and Earl, C. J. C. (1932). Tuberose sclerosis and allied conditions. Brain, 55, 311-346.

Crome, L. (1956). Pachygyria. J. Path. Bact., 71, 335-352.

Crome, L. (1957). Infantile cerebral gliosis with giant nerve cells. J. Neurol. Neurosurg. Psychiat., 20, 117-124.

Falconer, M. A., Serafetinides, E. A., and Corsellis, J. A. N. (1964). Etiology and pathogenesis of temporal lobe epilepsy. Arch. Neurol. (Chic.), 10, 233-248.

Goldie, L.. and Green, J. M. (1959). A study of the psychological factors in a case of sensory reflex epilepsy. Brain, 84, 508-524.

Gupta, S. K. (1956). An unusual case of tuberous sclerosis. Lancet, 2, 1289-1290.

Hallervorden, J., and Krücke, W. (1956). Die tuberöse Hirnsklerose. in Handbuch der speziellen pathologischen Anatomie und Histologie. Vol. 13, part 4, pp. 602-663. Edited by $\mathbf{O}$. Lubarsch, F. Henke, and R. Rössle. Springer: Berlin.

Jakob, A. (1914). Zur Pathologie der Epilepsie. Z. ges. Neurol. Psychiat. Originalien., 23, 1-65.

Kapp, J. P., Paulson, G. W., and Odom, G. L. (1967). Brain tumors with tuberous sclerosis. J. Neurosurg., 26, 191-202.

Meyer. A., Falconer, M. A., and Beck, E. (1954). Pathological findings in temporal lobe epilepsy. J. Neurol. Neurosurg. Psychiat., 17, 276-285.

Obrador, S. (1963). Some neurosurgical aspects of the socalled phakomatoses. J. Neurosurg., 20, 296-302.

Pampiglione, G., Evans, P. R., Harris, R., and Moynahan, E. J. (1968). Aspetti elettroclinici della sclerosi tuberosa. Atti Conf. Aggiorn. Soc. ital. Elettroenc. Neurofisiol., Naples, 1968. Pp. 73-85.

Perier, O., and Achslogh, J. (1965). Cure chirurgicale d'une épilepsie focale dans un cas de sclérose tubéreuse de Bourneville. Acta. neurol. belg., 65, 563-578.

Perot, P., Weir, B., and Rasmussen, T. (1966). Tuberous sclerosis. Surgical therapy for seizures. Arch. Neurol. (Chic.), 15, 498-506.

Rosman, N. P., and Pearce, J. (1967). The brain in multiple neurofibromatosis (von Recklinghausen's disease): a suggested neuropathological basis for the associated mental defect. Brain, 90, 829-838.

Yakovlev, P. I. (1939). Congenital morphologic abnormalities of the brain in a case of abortive tuberous sclerosis: functional implications and bearing on pathogenesis of so-called genuine epilepsy. Arch. Neurol. Psychiat. (Chic.), 41, 119-139. 